\title{
Interaction with Neuronal Calcium Sensor NCS-1 Mediates Desensitization of the D2 Dopamine Receptor
}

\author{
Nadine Kabbani,, Laszlo Negyessy, ${ }^{3}$ Ridwan Lin,, ${ }^{2}$ Patricia Goldman-Rakic, ${ }^{3}$ and Robert Levenson ${ }^{1}$ \\ ${ }^{1}$ Department of Pharmacology and ${ }^{2 N e u r o s c i e n c e ~ G r a d u a t e ~ P r o g r a m, ~ P e n n ~ S t a t e ~ C o l l e g e ~ o f ~ M e d i c i n e, ~ H e r s h e y, ~}$ \\ Pennsylvania 17033, and ${ }^{3}$ Department of Neurobiology, Yale University School of Medicine, New Haven, Connecticut \\ 06510
}

\begin{abstract}
Dopaminergic transmission within limbic regions of the brain is highly dependent on the regulation of D2 receptor activity. Here we show that the neuronal calcium sensor-1 (NCS-1) can mediate desensitization of D2 dopamine receptors. Analysis of D2 receptors expressed in human embryonic kidney 293 cells indicates that NCS-1 attenuates agonist-induced receptor internalization via a mechanism that involves a reduction in D2 receptor phosphorylation. This effect of NCS-1 was accompanied by an increase in D2 receptor-mediated cAMP inhibition after dopamine stimulation. The ability of NCS-1 to modulate D2 receptor signaling was abolished after a single amino acid mutation in NCS-1 that has been shown to impair the calciumbinding properties of NCS-1. Coimmunoprecipitation experiments from striatal neurons reveal that NCS-1 is found in
\end{abstract}

association with both the D2 receptor and G-protein-coupled receptor kinase 2, a regulator of D2 receptor desensitization. Colocalization of NCS-1 and D2 receptors was examined in both primate and rodent brain. In striatum, NCS-1 and D2 receptors were found to colocalize within sites of synaptic transmission and in close proximity to intracellular calcium stores. NCS-1-D2 receptor interaction may serve to couple dopamine and calcium signaling pathways, thereby providing a critical component in the regulation of dopaminergic signaling in normal and diseased brain.

Key words: dopamine receptor; neuronal calcium sensor-1; GRK; GPCR desensitization; frequenin; calcium signaling; yeast two-hybrid
Dopaminergic neurotransmission is mediated via the distinct signaling properties of D1-like (D1 and D5) and D2-like (D2, D3, and D4) dopamine receptor subfamilies (Civelli et al., 1993; Missale et al., 1998). A number of psychiatric disorders including Tourette's syndrome and schizophrenia are associated with imbalances in dopaminergic transmission, possibly caused by alterations in dopamine receptor signaling (Sealfon and Olanow, 2000). This idea is underscored by the fact that the majority of antipsychotic and neuroleptic drugs act as antagonists of D2-like receptors (Seeman, 1992). However, studies have failed to demonstrate that alterations in dopamine receptors themselves represent the underlying cause of schizophrenia (Henn, 1986). Therefore, it is possible that a dysregulation in dopaminergic signaling may be brought about through alterations in proteins that serve to regulate signaling through dopamine and other receptors.

Dopamine receptors belong to the superfamily of G-proteincoupled receptors (GPCRs) (Civelli et al., 1993). The processes of receptor desensitization and resensitization modulate signaling through GPCRs. Receptor desensitization, characterized by a decline in receptor responsiveness to agonist, represents a critical adaptation mechanism that protects against receptor overstimu-

\footnotetext{
Received Feb. 6, 2002; revised July 22, 2002; accepted July 24, 2002.

This work was supported by National Institute of Mental Health Grant P50MH44866. We thank Dr. Allan Levey (Emory University) for D2 dopamine receptor antibody and Dr. J. L. Benovic (Thomas Jefferson University) for GRK cDNA. We are grateful to Klara Szigeti for excellent assistance with electron microscopy. We thank Drs. Blaise Peterson, Clare Bergson, and Bernhard Luscher for helpful comments on this manuscript.

Correspondence should be addressed to Robert Levenson, Penn State College of Medicine, Department of Pharmacology, Hershey, PA 17033. E-mail: rlevenson@hmc.psu.edu.

Copyright (C) 2002 Society for Neuroscience $0270-6474 / 02 / 228476-11 \$ 15.00 / 0$
}

lation (Lohse, 1993; Krupnick and Benovic, 1998). However, receptor desensitization has been shown to limit the therapeutic usefulness of drugs that act as receptor agonists and may contribute to features of addiction (Nestler, 1995; Self, 1998). The desensitization of activated GPCRs is mediated by the phosphorylation of serine and threonine residues within the intracellular domains of receptors (Ferguson, 2001). Receptor phosphorylation serves to uncouple receptors from G-protein activation and promote arrestin binding and internalization (Krupnick and Benovic, 1998). Both second messenger-dependent kinases [e.g., protein kinase A (PKA) and protein kinase $\mathrm{C}(\mathrm{PKC})]$ and G-protein-coupled receptor kinases (GRKs) have been shown to contribute to the desensitization of activated dopamine receptors (Mason et al., 2002). Although originally thought to mediate agonist-dependent (homologous) and agonist-independent (heterologous) forms of receptor desensitization, both GRKs and second messenger kinases are now believed to contribute to both forms of receptor desensitization in a more complex manner (Ferguson, 2001). For example, the dopamine-induced desensitization of the D1 receptor appears to be regulated via both PKAand GRK-mediated pathways (Jiang and Sibley, 1999), whereas the internalization of activated D2 receptors is enhanced by coexpression of both GRK2 and GRK5 (Ito et al., 1999; Iwata et al., 1999). Therefore, it is likely that the mechanism underlying receptor desensitization, including the desensitization of subtypes of dopamine receptors, is modulated by the activity of proteins that can interact with both the receptor and its kinase.

To identify proteins involved in mediating D2 receptor signaling, we used the $\mathrm{C}$ terminus of the $\mathrm{D} 2$ receptor as bait to screen a human brain cDNA library. One clone isolated from this screen corresponds to neuronal calcium sensor-1 (NCS-1). NCS-1 is the 
mammalian ortholog of frequenin, a calcium-binding protein implicated in mediating several aspects of neurotransmission, including ion channel regulation (Weiss et al., 2000; Tsujimoto et al., 2002) and neurotransmitter release (McFerran et al., 1999; Pan et al., 2002; Scalettar et al., 2002). Our studies suggest an additional role for NCS-1 in modulating GRK-mediated desensitization of activated D2 dopamine receptors. Regulation of D2 receptor desensitization by NCS-1 may have significant implications for understanding dopaminergic signaling in normal brain and in neuropathologies characterized by a dysregulation in dopaminergic neurotransmission.

\section{MATERIALS AND METHODS}

DNA constructs and protein interaction assays. All constructs were generated by subcloning PCR amplification products into appropriate vectors, and each construct was verified by automated DNA sequencing. cDNA fragments encoding the $\mathrm{C}$ terminus of the D1 (residues 365-446), D2 (residues 428-443), D3 (residues 385-400), D4 (residues 370-387), and D5 (residues 360-477) receptors were ligated into the yeast GAL4 DNA-binding domain expression vector pAS2-1 (Clontech, Palo Alto, $\mathrm{CA})$. For the D2 receptor screen, the D2-pAS2-1 bait plasmid and the human brain cDNA library in the GAL4 activation domain vector pACT2 (Clontech) were simultaneously cotransformed into the yeast strain MaV103 as previously described (Lin et al., 2001). Positive clones were identified by growth on $\mathrm{Leu}^{-} / \mathrm{Trp}^{-} / \mathrm{His}^{-} / \mathrm{Ura}^{-}$selection plates. Protein interaction was assayed for by $\beta$-galactosidase activity via the nitrocellulose filter lift method (Lin et al., 2001).

To identify the sites of interaction between D2 or D3 receptors and NCS-1, truncated or full-length receptor constructs (in pAS2-1) were assayed for interaction against truncated or full-length NCS-1 constructs (in pACT2) using the yeast two-hybrid method. Bait and prey plasmids were simultaneously transformed into the yeast strain MaV103 and interactions were assayed as described above.

For expression studies, full-length NCS-1 cDNA was subcloned into the mammalian expression vectors pEGFP-N [C-terminal enhanced green fluorescent protein (EGFP) tag; Clontech] or pCB6 (Brewer and Roth, 1991). The calcium-defective NCS-1 mutant E120Q was generated by PCR mutagenesis as previously described (Weiss et al., 2000) and subcloned into the mammalian expression vector pEGFP-N. FLAGtagged D3 receptor cDNA was generated as previously described (Karpa et al., 2000).

Cell culture and transfection. Human embryonic kidney (HEK) 293 cells were maintained in DMEM supplemented with $10 \%$ fetal bovine serum. HEK 293 cells stably expressing FLAG-tagged D2L receptors (293-D2 cells) were provided by Dr. Mark von Zastrow (University of California, San Francisco). 293-D2 cells were maintained in DMEM supplemented with $10 \%$ fetal bovine serum and $300 \mu \mathrm{g} / \mathrm{ml}$ geneticin/ G418 (Invitrogen, Grand Island, NY). Cells were transfected using the Lipofectamine 2000 transfection reagent (Invitrogen, Carlsbad, CA) under conditions described by the manufacturer. Striatal cell cultures were prepared from embryonic day 18 (E18) rat embryos as previously described (Lin et al., 2001). Striatal cultures were maintained in Neurobasal media supplemented with $2 \%$ B-27 (Invitrogen), then treated with $10 \mu \mathrm{M} 5$-fluoro-5'-deoxyuridine (Sigma, St. Louis, MO) to eliminate glial proliferation. Experiments were performed on striatal cells maintained in culture for 2 weeks.

Glutathione S-transferase pull-down and coimmunoprecipitation. Fusion protein glutathione S-transferase (GST)-NCS-1 (amino acids 1-190) was constructed in the expression vector pGEX-4T-1 (Amersham Biosciences, Piscataway, NJ). GST-NCS-1 fusion protein was induced in Escherichia coli strain BL21 (DE3) then purified with glutathionesepharose (Amersham) according to manufacturer's instructions. GSTpull-down assays were performed as previously described (Lin et al., 2001). Eluted proteins were separated by SDS-PAGE and transferred to a nitrocellulose filter. The filter was probed with M2 anti-FLAG (1:1000 dilution of the monoclonal antibody; Sigma), anti-D2 receptor (1:500 dilution of the polyclonal antibody; Santa Cruz Biotechnology, Santa Cruz, CA), and anti-GRK2 (1:1000 of the polyclonal antibody, Santa Cruz Biotechnology) antibodies.

Immunoprecipitations were performed from crude membranes or total cell lysates as previously described by Karpa et al. (2000). FLAG-tagged D2 and D3 receptors were immunoprecipitated using the M2 anti-FLAG monoclonal antibody. Native D2 receptors were immunoprecipitated with a polyclonal anti-D2 receptor antibody (Calbiochem, San Diego, CA), whereas NCS-1 was immunoprecipitated using a polyclonal antifrequenin antibody (Rockland Immunochemicals, Gilbertsville, PA). Western analysis of immunoprecipitated complexes was performed by using polyclonal anti-frequenin antibody (Rockland Immunochemicals), polyclonal anti-GRK2 antibody (Santa Cruz Biotechnology), or polyclonal anti-D2 receptor antibody (Santa Cruz Biotechnology). To block protein kinase A activity, HEK 293 cells were treated with $10 \mu \mathrm{M}$ of the PKA inhibitor H-89 (2-( $p$-bromocinnamylamino)ethyl-5-Isoquinolinesufonamide; Sigma) for $30 \mathrm{~min}$.

Immunofluorescence. HEK 293 cells were transiently transfected with plasmids encoding either FLAG-tagged D2 or FLAG-tagged D3 receptors. Detection of dopamine receptors was done by immunostaining with anti-FLAG M2 monoclonal (1:1000 dilution of the monoclonal antibody; Sigma). Immunofluorescence was visualized by confocal laser microscopy using a Zeiss LSM 210 confocal microscope. For immunostaining of striatal cultures, cells were fixed and permeabilized as previously described (Lin et al., 2001). Double and triple labeling was performed by overnight incubation with combinations of the following antibodies: NCS-1 (1:600 dilution of a chicken polyclonal anti-frequenin antibody; Rockland Immunochemicals), D2 receptor (1:2000 dilution of a rabbit polyclonal antibody; Calbiochem, San Diego, CA, or 1:1000 dilution of a goat polyclonal antibody; Santa Cruz Biotechnology), GRK2 (1:400 dilution of a rabbit polyclonal antibody; Santa Cruz Biotechnology), and microtubule-associated protein 2 (MAP2) (1:1500 dilution of a rabbit polyclonal antibody; Chemicon, Temecula, CA). Double staining was visualized with a 1:200 dilution of FITC-goat anti-rabbit and Red-X goat anti-chicken secondary antibodies, whereas triple labeling was visualized with a 1:200 dilution of FITC donkey anti-goat, AMCA donkey antichicken, and Red-X donkey anti-rabbit antibodies (Jackson ImmunoResearch, West Grove, PA). Fluorescent images were obtained with a Zeiss Axiophot System and captured with QED imaging software.

Immunoelectron microscopy. Animals used for immunohistochemistry were housed and treated according to institutional guidelines. Three adult Wistar rats and two adult rhesus monkeys (Macaca mulatta) of both sexes were perfused, and brain tissue was prepared as described (Mrzljak et al., 1998). Sections of striatum were incubated with a cocktail of NCS-1 (1:100 dilution, chicken polyclonal anti-frequenin antibody; Rockland Immunochemicals) and D2 receptor (1:60 or 1:100 dilution; Levey et al., 1993) antibodies. Primary antibodies were complexed with a mixture of biotinylated goat anti-chicken (1:200; Vector Laboratories, Burlingame, CA) and $1 \mathrm{~nm}$ gold-coupled goat anti-rabbit (1:50 dilution; Amersham) secondary antibodies. To visualize immunogold-labeled D2 receptors, silver enhancement of the gold particles was performed using the IntenSe intensification kit (Amersham). NCS-1 immunocomplexes were detected by Vectastain ABC Elite kit (Vector Laboratories) and visualized by DAB (3'3-diaminobenzodine; Sigma) reactions. Sections were flat embedded in Durcupan ACM (Fluka, Milwaukee, WI). Ultrathin sections were poststained with lead citrate and examined on a JEOL 1010 transmission electron microscope.

Cleavable biotin and $c A M P$ assays. Receptor internalization and cell surface labeling assays were performed using the cleavable biotin method as described by Vickery and von Zastrow (1999). Briefly, cells were labeled with $1 \mathrm{mg} / \mathrm{ml}$ cleavable sulfo-NHS-S-S-biotin (Pierce, Rockford, IL) for $30 \mathrm{~min}$ at $4^{\circ} \mathrm{C}$. Cell surface biotin was then cleaved by exposing cells to glutathione strip buffer (Vickery and von Zastrow, 1999). Biotinlabeled D2 or D3 receptors were immunoprecipitated using the M2 anti-FLAG monoclonal antibody, resolved by SDS-PAGE, and transferred to a nitrocellulose filter. Biotinylated receptors were complexed with horseradish peroxidase using the Vectastain ABC detection system, then detected by enhanced chemiluminescence with an ECL Plus kit (Amersham). Quantification of immunoblots was performed by laser densitometry (Molecular Dynamics, Sunnyvale, CA) and analyzed using the Quantity One software package (PDI, Inc.). Internalized receptors are expressed as a percentage of total surface receptors in membranes that had not been subject to biotin cleavage.

cAMP assays were performed on cell lysates prepared from 293-D2 cells transiently transfected with either wild-type NCS-1 or the E120Q NCS-1 mutant. In some experiments, cells were subjected to a $12 \mathrm{hr}$ preincubation with $100 \mu \mathrm{g} / \mathrm{ml}$ pertussis toxin (Calbiochem) before initiation of the cAMP assay. Measurement of total intracellular cAMP was performed using a cAMP enzyme immunoassay kit (Amersham) according to instructions provided by the manufacturer. Statistical analysis was performed using the Statistica software package.

Whole-cell phosphorylation assays. Whole-cell phosphorylation assays 
were performed essentially as described by Tiberi et al. (1996). 293-D2 cells were transfected with $10 \mu \mathrm{g}$ of DNA $1 \mathrm{~d}$ before the assay. Cells plated onto 6-well dishes at a density of $1 \times 10^{6} /$ well were labeled with $0.2 \mathrm{mCi} / \mathrm{ml}{ }^{32} \mathrm{P}_{\mathrm{i}}$ for $3 \mathrm{hr}$ then treated with dopamine. All samples were normalized to total protein concentration. Phosphorylated receptors were immunoprecipitated with anti-FLAG M2 monoclonal antibody, then resolved by SDS-polyacrylamide gel electrophoresis. Gels were dried and exposed to X-OMAT/Biomax film (Eastman Kodak, Rochester, NY) at $-80^{\circ} \mathrm{C}$ for $5-12 \mathrm{hr}$. Receptor phosphorylation was quantified using Quantity One software (Molecular Dynamics).

\section{RESULTS}

\section{Interaction of NCS-1 with dopamine receptors}

To identify dopamine receptor interacting proteins, we used the $\mathrm{C}$ terminus of the D2 dopamine receptor (amino acid residues 428-443) to screen an adult human brain cDNA library. In control experiments the bait did not cause autologous activation of the reporter gene, as indicated by lack of $\beta$-galactosidase activity (data not shown). Of the $5 \times 10^{5}$ clones screened, one was found to contain the complete open reading frame (ORF) for human NCS-1. NCS-1 is a highly conserved member of the NCS family of calcium binding proteins, which includes neurocalcin, hippocalcin, and recoverin. NCS-1 is the mammalian ortholog of the Drosophila and Xenopus frequenin protein (Pongs et al., 1993; Nef et al., 1995; Olfasson et al., 1995). NCS-1 possesses three functional and one vestigial EF-hand calcium binding domains and has been shown to mediate several aspects of neurotransmission (Burgoyne and Weiss, 2001).

To examine the specificity of the D2 receptor-NCS-1 interaction, we used the yeast two-hybrid system to test the interaction of NCS-1 with additional dopamine receptor family members. Bait constructs encoding the C-terminal segments of the D1, D2, D3, D4, and D5 receptors were tested for interaction with NCS-1. Using this assay, we found that NCS-1 interacts with the D2, D3, and D5 receptors, but not with the D1 or D4 receptor subtypes. These results indicate that NCS-1 can associate with some but not all members of the D1-like and D2-like subfamilies in the yeast system.

To confirm interaction between NCS-1 and the D2 receptor, we tested the ability of D2 receptors to associate with a GST fusion protein containing the complete NCS-1 ORF. Crude membranes were prepared from 293-D2 cells and tested for the ability to associate with the GST-NCS-1 fusion protein. As shown in Figure $1 A$, a Western blot containing crude membranes prepared from 293-D2 cells produced a $44 \mathrm{kDa}$ band immunoreactive with the anti-FLAG M2 monoclonal antibody. This band corresponds in size to FLAG-tagged D2 receptors detected in unadsorbed cell lysates. Immunoreactive D2 receptors were not visualized when membranes were adsorbed onto GST alone or when membranes were prepared from nontransfected HEK 293 cells.

Interaction between dopamine receptors and NCS-1 was also verified by coimmunoprecipitation experiments. To demonstrate interaction, we tested the ability of an anti-green fluorescent protein (GFP) antibody to coimmunoprecipitate NCS-1 and D2 receptors from 293-D2 cells transiently expressing GFP-tagged NCS-1. As shown in Figure $1 B$, anti-GFP antibody was capable of coimmunoprecipitating D2 receptors. We also tested the ability of an anti-GFP antibody to coimmunoprecipitate NCS-1 and D3 receptors from HEK 293 cells transiently transfected with GFPtagged NCS-1 plus FLAG-tagged D3 receptors. As shown in Figure $1 C$, anti-GFP antibody was capable of coimmunoprecipitating D3 receptors in these cells. In these experiments, FLAG-

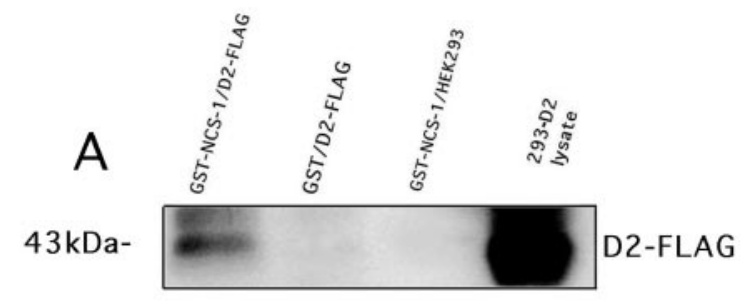

IB: anti-FLAG
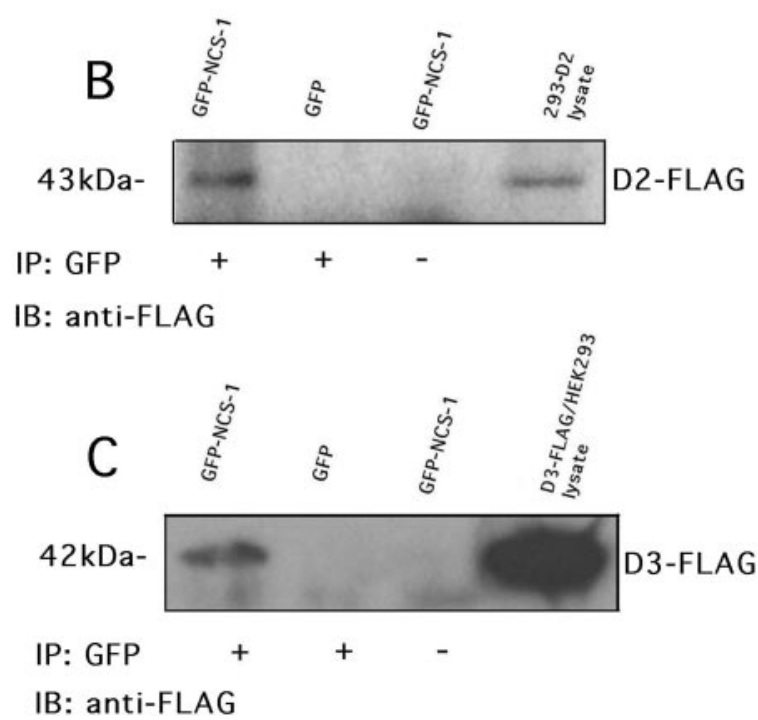

Figure 1. Interaction of D2 dopamine receptor with NCS-1. A, GSTNCS-1 fusion protein was used to pull-down the D2 receptor from crude membrane preparations of 293-D2 cells. FLAG-tagged D2 receptors were detected in unabsorbed cell lysates and pull-down lanes using FLAGspecific M2 antibodies. Coimmunoprecipitation of NCS-1 with D2 receptors $(B)$ or D3 receptors $(C)$. An anti-GFP antibody was used to immunoprecipitate GFP-NCS-1 from crude membrane preparations of 293-D2 cells transiently transfected with GFP-NCS-1 (B), or HEK 293 cells transiently transfected with both GFP-NCS-1 and FLAG-tagged D3 receptors $(C)$. Blots were probed for either D2 or D3 receptors using anti-FLAG M2 antibodies.

tagged D2 and D3 receptors were not coimmunoprecipitated from cells transfected with GFP alone or when the GFP antibody was omitted from the immunoprecipitation reaction. Taken together, these studies provide strong evidence for an association between NCS-1 and D2-like dopamine receptors in transfected mammalian cells.

\section{Mapping protein interaction domains}

We performed deletion mapping studies to localize sites within NCS-1 that contribute to NCS-1-D2 receptor interaction. A series of truncation fragments of NCS-1 were tested for their interaction with the $\mathrm{C}$ terminus of the $\mathrm{D} 2$ receptor (amino acids 428-443) in the yeast two-hybrid assay. As shown in Figure $2 A$, a minimal fragment containing the $\mathrm{N}$-terminal 71 residues of NCS- 1 tested positive in the $\beta$-galactosidase assay. A construct encoding residues $72-190$ of NCS-1 did not interact with the C terminus of the $\mathrm{D} 2$ receptor, confirming that the $\mathrm{N}$ terminus of NCS-1 (amino acids 1-71) is essential for D2-NCS-1 interaction. Deletion analysis was also used to identify the site within the $\mathrm{C}$ terminus of the D2 receptor that contributes to the interaction with NCS-1. The 16-amino acid (aa)-long D2 tail (aa 428-443) was subdivided into two fragments corresponding to residues 428-436 and 437-443. As shown in Figure $2 B$, the fragment containing 
A

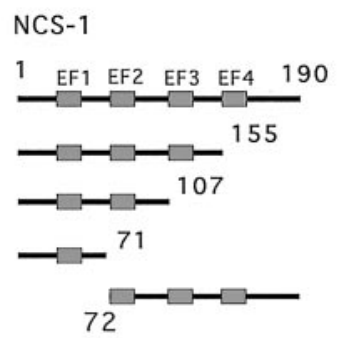

B

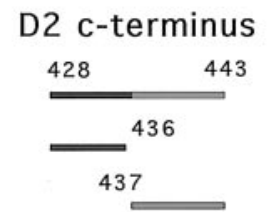

C

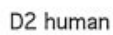

D3 human

D4 human
$+$

$+$

$+$

$+$

$-$

Interaction with NCS-1

$+$

$+$

$-$
Interaction with D2

Figure 2. D2 receptor and NCS-1 interaction domains. A, Schematic representation of constructs encoding truncations of NCS-1. Constructs were tested for interaction with the C-terminal tail of the D2 receptor in the two-hybrid assay. Interaction is indicated by the presence or absence of $\beta$-galactosidase activity. Note: all NCS- 1 constructs produced approximately the same intensity of $\beta$-galactosidase staining. $B$, Constructs encoding truncations of the D2 C-terminal tail (aa 428-443) were tested for interaction with full-length NCS-1 in the two-hybrid assay as above. C, Amino acid sequence alignment of the $\mathrm{C}$-terminal domains of the human D2, D3, and D4 receptors. Residues conserved between the three receptors are boxed, whereas residues within the putative transmembrane domains are shaded.

residues $428-436$ tested positive, whereas the fragment containing residues $437-443$ tested negative in the $\beta$-galactosidase assay. An alignment of the $\mathrm{C}$ termini of the $\mathrm{D} 2$-like dopamine receptors is shown in Figure $2 C$. Within the interacting segment, the D2 and D3 receptors are identical, whereas the D4 receptor differs at three of the nine positions. These nonconserved residues are likely to be critical for the interaction of D2 and D3 receptors with NCS-1.

\section{Interaction of NCS-1 and D2 receptors in cultures of rat striatum}

To further characterize NCS-1-D2 receptor interaction, we examined the expression of NCS-1 and D2 receptors in cultures of rat striatum. In double-labeling experiments, coexpression of NCS-1 and the neuronal marker MAP2 was detected within somatic and dendritic neuronal regions (Fig. 3A-C). NCS-1 did not colocalize with the astrocytic marker glial fibrillary acidic protein (GFAP) (data not shown). Double labeling with anti-D2 and anti-NCS-1 antibodies indicates colocalization of the proteins within somata and processes of striatal neurons (Fig. 3D-I). These observations suggest that NCS-1 colocalizes with D2 receptors in striatal neurons. Coimmunoprecipitation experiments were performed to test whether NCS-1 and D2 receptors can associate in striatal cultures. D2 receptors were immunoprecipitated from striatal membrane preparations and immunocomplexes probed for the presence of NCS- 1 . Western blot analysis using anti-NCS-1 antibodies showed the presence of an $\sim 22 \mathrm{kDa}$ band whose mobility is virtually coincident with that of endogenous NCS-1 expressed in HEK 293 cells (Fig. 3J). This band was not detected in mock immunoprecipitations in which the anti-D2 receptor antibody was omitted or in immunoprecipitations using a nonspecific antibody. These results indicate that NCS-1 and D2 receptors can associate in striatal neurons.

\section{NCS-1 and D2 receptors colocalize at sites of synaptic activity}

Double immunoelectron microscopic analysis of rat and monkey striatum was used to gain insight into the subcellular distribution of NCS-1 and D2 dopamine receptors. NCS-1 immunoreactivity was localized in dendrites, spines, and occasionally in axonal boutons in the neuropil of the rat and monkey striatum. In double-labeling experiments, dendrites and spines were the most frequently observed structures exhibiting both NCS-1 and D2 receptor immunoreactivity (Fig. $4 a-g$ ). In monkey striatum, D2 and NCS-1 immunoreactivity was found in very close proximity, and sometimes overlapped, within dendrites (Fig. 4a-c). A similar overlapping expression of NCS-1 and D2 receptors was also detected within the spines of both monkey (Fig. 4d,e) and rat (Fig. $4 f, g$ ) striatum. Spines coexpressing NCS-1 and D2 receptors usually formed asymmetric synaptic contacts with axon terminals containing round synaptic vesicles (Fig. $4 d-g$ ). Within doublelabeled structures, immunometal particles representing D2 receptor immunoreactivity were often associated with the cytoplasmic surface of the plasma membrane and were found peri- and/or extrasynaptically (Fig. 4a-g). Morphological characterization of the double labeling indicates that D2-NCS-1 complexes are situated in close proximity to intracellular calcium stores. This is the case in spines where double labeling is often associated with the spine apparatus (Fig. 4f,g) and in dendrites where immunolabeling associated with the plasma membrane was often found in close proximity to mitochondria (Fig. $4 a-c$ ). Given that the method used does not allow preservation of the fine membranous structures of the endoplasmic reticulum, it is highly likely that the immunolabeling pattern observed in dendrites represents sites where intracellular calcium stores approach the neuronal plasma membrane (Berridge, 1998). The close spatial proximity of D2 receptor and NCS-1 immunoreactivity provides compelling evidence for an interaction between these two proteins within neurons.

\section{NCS-1-D2 receptor interaction attenuates ligand-induced D2 receptor internalization}

To determine the functional significance of NCS-1-D2 receptor interaction, we examined the effect of overexpressing NCS-1 on D2 receptor signaling. HEK 293 cells were found to endogenously express NCS-1. A 10 -fold increase in NCS-1 expression was observed after transient transfection of HEK 293 cells with an EGFP-tagged NCS-1 construct (data not shown). Members of the NCS family are predicted to play a role in regulating desensitization of GPCRs (Burgoyne and Weiss, 2001). We used a cleavable biotin assay to analyze the effect of NCS-1 on D2 receptor internalization. In 293-D2 cells, D2 receptors exhibit agonist-independent-constitutive internalization. Consistent with previous reports (Vickery and von Zastrow, 1999), we found that dopamine stimulation increases the net internalization of D2 receptors twofold to threefold (Fig. $5 A$ ). The effects of dopamine on $\mathrm{D} 2$ receptor internalization were virtually abolished in the presence of $1 \mu \mathrm{M}$ of the selective D2 receptor antagonist haloperidol (Fig. 5A). In 293-D2 cells, overexpression of EGFPNCS-1 did not significantly alter the total number of D2 receptors present at the plasma membrane in the absence of dopamine stimulation (Fig. 5B) (Student's two tailed $t$ test; $n=3 ; p<.05$ ). Therefore, we examined the effect of NCS-1 overexpression on 

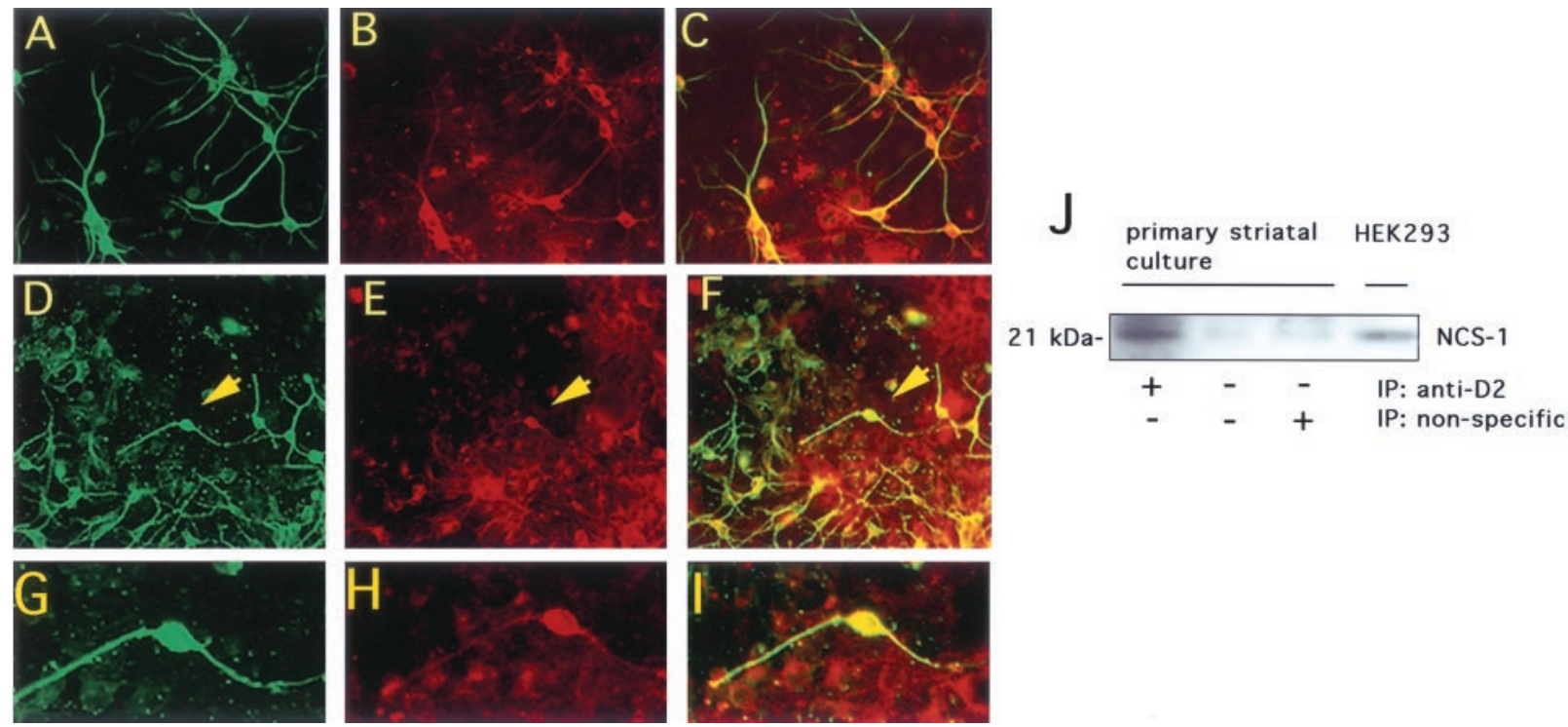

Figure 3. Expression of NCS-1 and D2 receptors in primary striatal neurons from rat brain. Detection of anti-MAP2 $(A)$ and anti-NCS-1 $(B)$ in double labeling within neurons. Merged image $(C)$ shows MAP2 and NCS-1 coexpression within neuronal perikarya and dendritic process of virtually all striatal neurons. Detection of D2 receptors $(D)$ and NCS-1 $(E)$ in double-labeled cultures. Merged image $(F)$ shows D2 receptor and NCS-1 coexpression within the cell body and processes of neurons. High magnification of a representative neuron (indicated by arrowheads in $D-F$ ) showing expression of D2 receptors $(G)$, NCS-1 $(H)$, and colocalization of the two proteins $(I)$. Numerous D2-positive, NCS-1-negative cells display an apparent astrocytic morphology $(D-F) . J$, Interaction of D2 receptors and NCS-1 in striatal cultures Anti-D2 receptor antibody was used to immunoprecipitate D2 receptors from crude membrane preparations of striatal cells. Immunocomplexes were then probed with anti-NCS-1 antibodies. The position of NCS-1 endogenously expressed in HEK 293 cell membranes is shown (HEK 293 lane).

D2 receptor internalization after dopamine treatment. As shown in Figure $5 C$, expression of EGFP-NCS-1 produced an $\sim 50 \%$ decrease in the total number of D2 receptors internalized following dopamine stimulation as compared with nonstimulated control cells. These results indicate that NCS-1 can modulate ligandinduced internalization without altering ligand-independent internalization of the D2 receptor.

\section{NCS-1 overexpression attenuates GRK-mediated internalization of D2 and D3 receptors}

We also examined the effect of NCS-1 overexpression on GRKmediated internalization of activated D2 and D3 dopamine receptors. In these experiments, FLAG-tagged D2 or D3 receptors were transiently transfected into HEK 293 cells, and receptor internalization was monitored via confocal microscopy and receptor biotinylation assays. In HEK 293 cells, D2 and D3 receptors were found predominantly at the plasma membrane in the absence of dopamine stimulation (Fig. 6A,D). After dopamine treatment both the D2 and D3 receptor subtypes exhibited a time-dependent translocation from the plasma membrane to cytosolic compartments (Fig. 6A-F). Consistent with previous reports (Kim et al., 2001), we found that the D3 receptor was more resistant to homolgous desensitization when compared with the D2 receptor (Fig. 6). Overexpression of GRK2 and GRK3 has previously been shown to augment ligand-mediated sequestration of D2 and D3 receptors, respectively (Kim et al., 2001). We found that overexpression of GRK2 greatly enhanced the agonistinduced internalization of the D2 receptor (Fig. 6G), whereas overexpression of GRK3 resulted in only a modest increase in D3 receptor internalization (Fig. 6H). As shown in Figure 6, NCS-1 was found to attenuate the number of D2 $(G)$ and D3 $(H)$ receptors internalized in the presence of GRK overexpression. It is noteworthy that NCS-1 appeared to have a more pronounced effect on D2 versus D3 receptor internalization, although the significance of this effect is not yet clear.

\section{NCS-1-D2 receptor interaction attenuates receptor phosphorylation and enhances D2 receptor signaling}

To determine the effect of NCS-1 on GRK-mediated phosphorylation of the D2 receptor, we measured D2 receptor phosphorylation in 293-D2 cells. In these cells, D2 receptor phosphorylation increased by more than twofold after $10 \mathrm{~min}$ of dopamine treatment (Fig. $7 B$ ). As shown in Figure $7 A$, dopamine-induced D2 receptor phosphorylation in 293-D2 cells was enhanced by the overexpression of GRK2, GRK3, and GRK5. Previous reports have shown GRK2 to be a potent regulator of D2 receptor phosphorylation (Ito et al., 1999; Iwata et al., 1999; Kim et al., 2001). We therefore examined the effects of GRK2 overexpression on D2 receptor phosphorylation. Compared with control cells, overexpression of GRK2 resulted in approximately a twofold increase in dopamine-mediated D2 receptor phosphorylation (Fig. 7B). NCS-1 appeared to reduce D2 receptor phosphorylation in the presence of GRK2 overexpression, but this effect was not found to be statistically significant. However, in the absence of GRK2 overexpression, NCS-1 alone produced a significant decrease in D2 receptor phosphorylation compared with controls (Fig. 7B). Taken together, these findings suggest that NCS-1 attenuates dopamine-induced D2 receptor phosphorylation.

In most mammalian cell lines, activation of $\mathrm{D} 2$ receptors leads to a decrease in intracellular cAMP levels via coupling of these receptors to inhibitory subsets of G-proteins (Missale et al., 1998). We examined the effect of NCS-1-D2 interaction on D2 receptor-mediated cAMP signaling in 293-D2 cells overexpressing EGFP-NCS-1. In 293-D2 cells, pretreatment with the $\mathrm{G}_{\mathrm{i} / \mathrm{o}}$ inhibitor pertussis toxin virtually abolished the effect of dopamine on cAMP inhibition (Fig. 7C). After a $10 \mathrm{~min}$ exposure of 

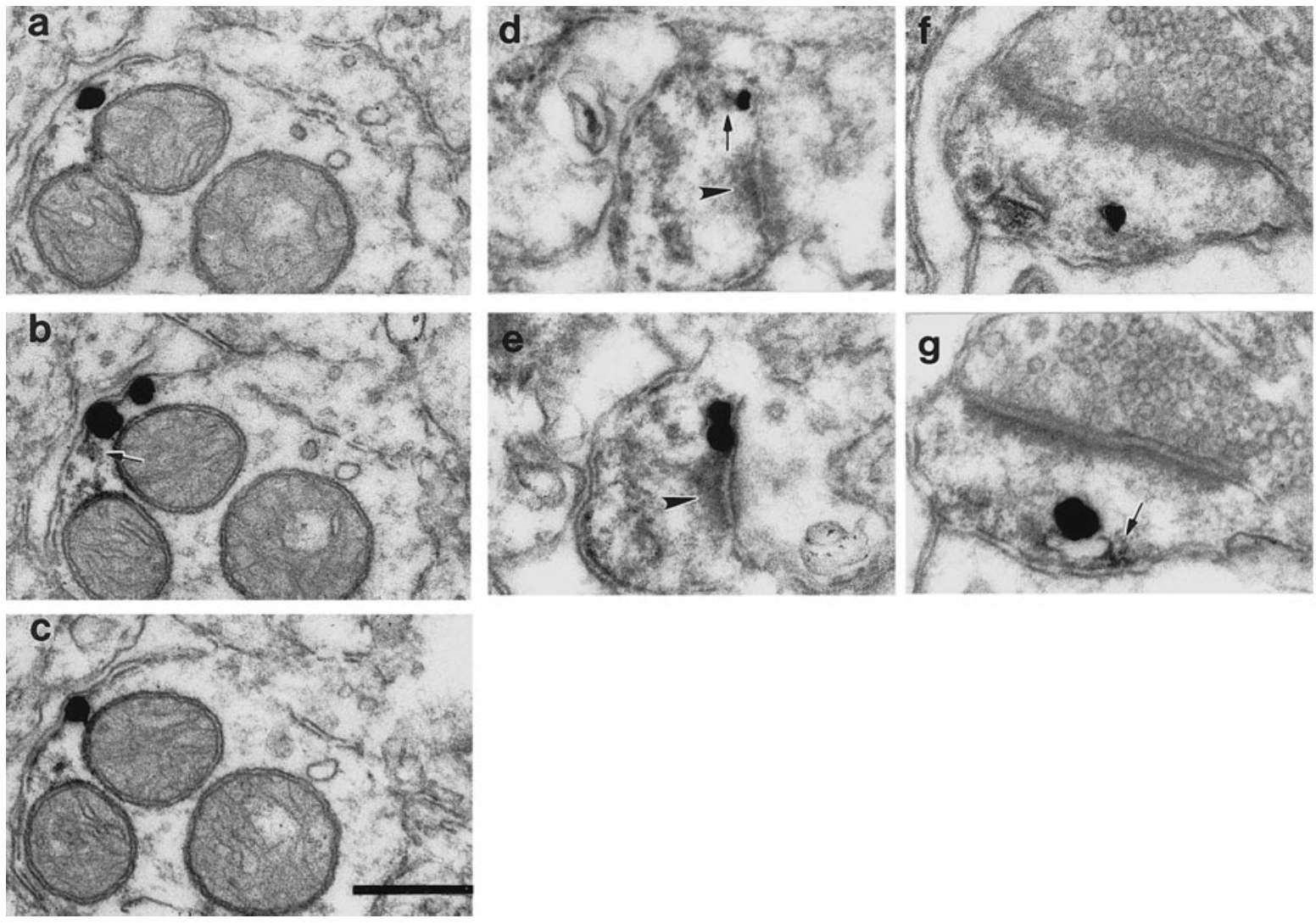

Figure 4. NCS-1 and D2 receptors colocalize within dendritic shafts and spines. Representative images of immunolabeling of NCS-1 (DAB reaction product) and D2 (immunometal particles) receptors within dendritic shafts $(a-c)$ and spines $(d-g)$ of neurons within monkey $(a-e)$ and rat $(f, g)$ striatum. Silver grains (representing D2 receptors) were detected extrasynaptically $(a-d, f, g)$ and perisynaptically $(e)$. Within dendritic spines, the spine apparatus appears to be immunoreactive for NCS-1 $(d-g)$. D2 receptor immunoreactivity is associated with the membrane of the NCS-1-immunoreactive spine apparatus $(f, g)$. Note the close spatial contiguity of DAB deposits (arrows) and silver particles in the dendrite as well as within spines $(b, d, g)$. An immunonegative spine is present in the top right corner of $a-c$. Arrowheads point to the postsynaptic density of asymmetric synaptic contacts $(d, e)$. Scale bar, $200 \mathrm{~nm}$.

cells to $10 \mu \mathrm{M}$ dopamine, we found a significant increase $(28.1 \%)$ in dopamine-mediated inhibition of total cellular cAMP in cells overexpressing NCS-1 compared with nontransfected controls (Fig. 7C). This effect of NCS-1 was also abolished after pretreatment of cells with pertussis toxin, suggesting that NCS-1 overexpression is associated with enhanced D2 receptor signaling via $\mathrm{G}_{\mathrm{i} / \mathrm{o}}$ pathways (Fig. $7 C$ ).

We investigated the effects of calcium binding to NCS-1 on D2 receptor signaling by expressing an NCS-1 mutant (E120Q) in 293-D2 cells. The E120Q mutation occurs in the third EF calcium-binding hand of NCS-1 and prevents the protein from undergoing calcium-dependent conformational changes (Weiss et al., 2000). Coimmunoprecipitation experiments indicate that the E120Q interacts as strongly with D2 receptors as does wild-type NCS-1 (N. Kabbani, unpublished observations). As shown in Figure $7 D$, the effect of dopamine on intracellular cAMP levels was not significantly different between 293-D2 cells transfected with E120Q and control cells. These results suggest that a calcium-dependent conformational change in NCS-1 is likely to be involved in modulating D2 receptor signaling.

\section{D2 receptors, NCS-1, and GRK2 form a signaling complex}

Members of the neuronal calcium sensor family have been reported to directly interact with GRKs and regulate signaling through GPCRs (Sallese et al., 2000; Burgoyne et al., 2001). We examined the ability of NCS-1 to associate with GRK2 by performing coimmunoprecipitation experiments on crude membranes prepared from 293-D2 cells. NCS-1 was immunoprecipitated from the cells, and immunocomplexes were probed for the presence of GRK2. As shown in Figure 8A, an immunoreactive band of $\sim 70 \mathrm{kDa}$ that comigrated with GRK2 was detected with anti-GRK2 antibodies. The ability to coimmunoprecipitate GRK2 (endogenously expressed in HEK 293 cells) with NCS-1 was greatly enhanced by exposure of cells to the cAMP-elevating agent forskolin $(100 \mu \mathrm{M})($ Fig. $8 A)$. Similar results were obtained when cells were treated with $1 \mathrm{~mm}$ dibutyryl cAMP (data not shown). When the same blot was reprobed with anti-D2 receptor antibodies, an immunoreactive band corresponding to the D2 receptor was detected predominantly in the forskolin-treated cells (Fig. 8B). Taken together, these results suggest that D2 receptors, NCS-1, and GRK2 form a complex within HEK 293 cells, and that the interaction between these proteins may be mediated via activation of cAMP signaling pathways.

It is well documented that stimulation of cAMP signaling pathways is associated with enhanced PKA activity (Pawson and Scott, 1997). We therefore examined the effect of PKA activation on NCS-1-GRK2 interaction in 293-D2 cells pretreated with the PKA specific-inhibiting agent H-89. As shown in Figure $8 C$, exposure of 293-D2 cells to $10 \mu \mathrm{M} \mathrm{H}-89$ before forskolin treatment markedly reduced NCS-1-GRK2 interaction. These results 

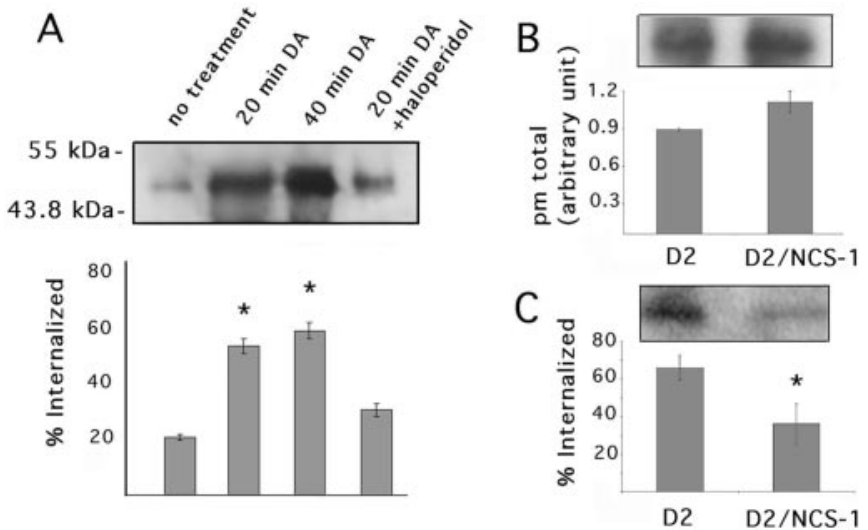

Figure 5. NCS-1-D2 interaction attenuates D2 receptor internalization. 293-D2 cells were transiently transfected with expression plasmids encoding either EGFP-NCS-1 or EGFP alone. A cleavable biotinylation assay was used to examine the effect of NCS-1 on D2 receptor internalization. $A$, Anti-FLAG M2 antibody was used to immunoprecipitate $\mathrm{D} 2$ receptors from lysates of cells treated with $10 \mu \mathrm{M}$ dopamine for $20 \mathrm{~min}, 10 \mu \mathrm{M}$ dopamine for $40 \mathrm{~min}, 10 \mu \mathrm{M}$ dopamine for $20 \mathrm{~min}$ in the presence of $1 \mu \mathrm{M}$ haloperidol, or untreated controls. $B$, Anti-FLAG antibody was used to immunoprecipitate $\mathrm{D} 2$ receptors from crude membranes prepared from biotinylated cells. The ratio of D2 receptor expressed at the cell surface was normalized to total $\mathrm{D} 2$ receptor to obtain the relative value of plasma membrane $(\mathrm{pm})$ expression. $C$, Anti-FLAG M2 antibody was used to immunoprecipitate D2 receptors from total lysates of cells treated with 10 $\mu \mathrm{M}$ dopamine for $20 \mathrm{~min}$. The asterisks refer to Student's $t$ tests performed to indicate statistical significance between groups; $\mathrm{p} \leq 0.05$.

suggest that the effect of forskolin on NCS-1-GRK2 interaction is mediated by activation of PKA.

Association between NCS-1-D2 receptor and NCS-1-GRK2 was also examined under differing calcium conditions. Total cell lysate prepared from 293-D2 cells was tested for the ability to associate with GST-NCS-1 fusion protein in the presence or absence of calcium. As shown in Figure $8 D$, an immunoreactive band corresponding to endogenous GRK2 was detected when calcium was present in the pull-down. When the same blot was stripped and reprobed with anti-D2 receptor antibodies, a $44 \mathrm{kDa}$ band immunoreactive with the anti-D2 receptor antibody was detected either when calcium was present or chelated in the pull-down assay (Fig. 8E). These results indicate that association between NCS-1 and the D2 receptor is calciumindependent, whereas, association between NCS-1 and GRK2 is calcium-dependent.

Interaction between NCS-1 and GRK2 was also tested in the absence of D2 receptor expression. In these experiments, GST-NCS-1 fusion proteins were tested for their ability to associate with GRK2 (endogenously expressed in HEK 293 cells) at various calcium concentrations. As shown in Figure $8 F$, an immunoreactive band corresponding to native GRK2 was detected at calcium concentrations in the pull-down reaction ranging from $100 \mathrm{nM}-10 \mu \mathrm{M}$. Consistent with earlier findings, GRK2 failed to associate with NCS-1 in the presence of the calcium chelator EDTA. These results indicate that NCS1-GRK2 interaction can occur in the absence of the D2 receptor, and that association between these two proteins may ensue over a broad range of intracellular calcium concentrations.

We used triple label immunofluorescence to determine whether NCS-1, D2 receptors, and GRK2 colocalize within neurons. In striatal cultures, many neurons coexpress all three pro-
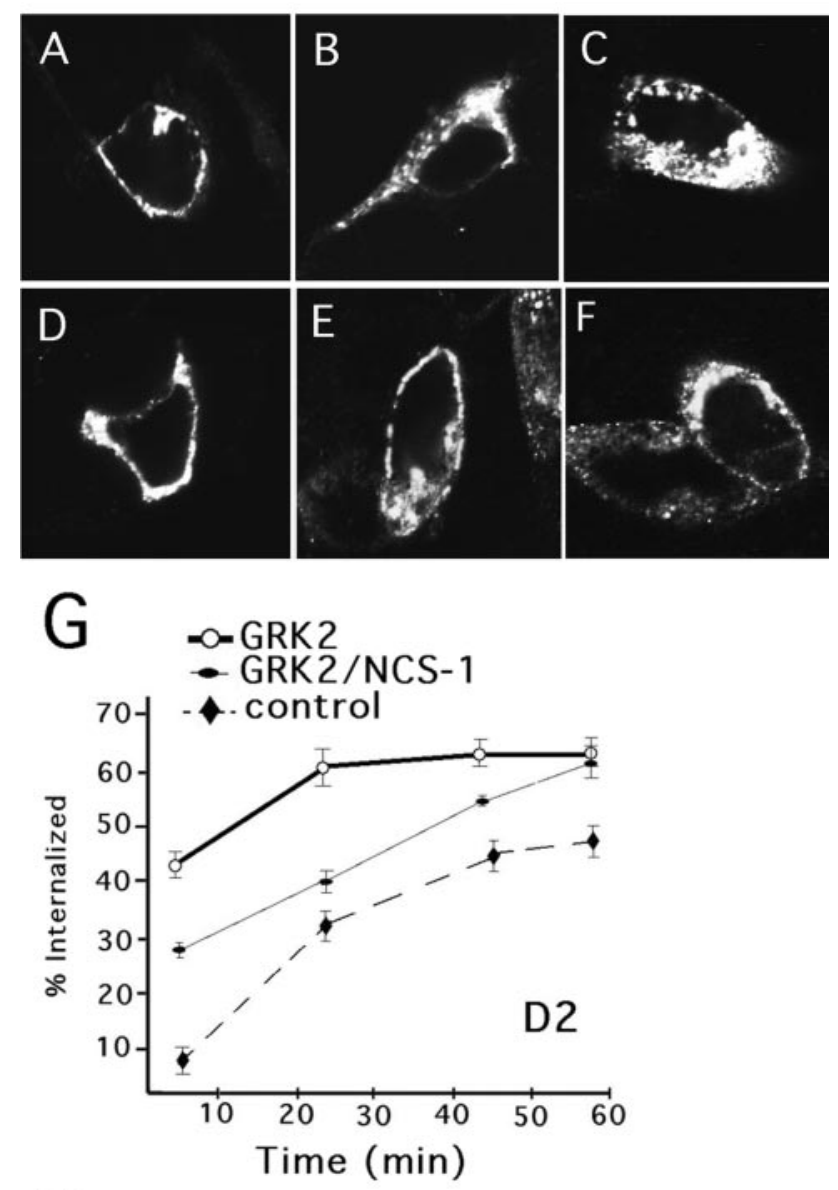

$\mathrm{H}$

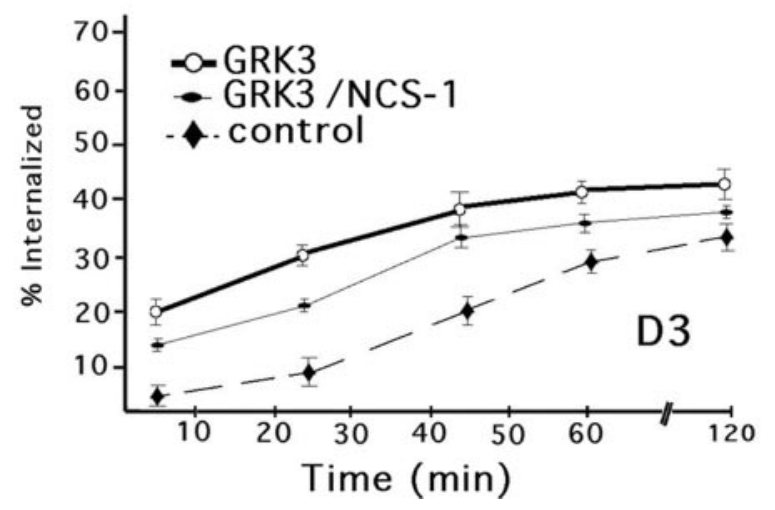

Figure 6. Effect of NCS-1 on D2-D3 receptor internalization. Confocal images of HEK 293 cells transiently transfected with FLAG-tagged D2 $(A-C)$ or FLAG-tagged D3 $(D-F)$ receptors. Representative images of cells stained with anti-FLAG M2 antibody. $A, D$, No dopamine; $10 \mu \mathrm{M}$ dopamine treatment for $25(B, E)$; or $60 \mathrm{~min}(C, F)$. A cleavable biotinylation assay was used to examine the effect of NCS-1 on D2 receptor internalization in the presence of GRK2 overexpression $(G)$, and D3 receptor internalization in the presence of GRK3 overexpression $(H)$.

teins (Fig. 9A-C). Overlapping staining of NCS-1, D2 receptors, and GRK2 was detected predominantly in cell bodies and dendritic processes (Fig. 9D). NCS-1 was immunoprecipitated from lysates of primary striatal neurons and immunocomplexes probed for the presence of GRK2. As demonstrated in Figure 9E, an immunoreactive band corresponding to GRK2 was detected in 

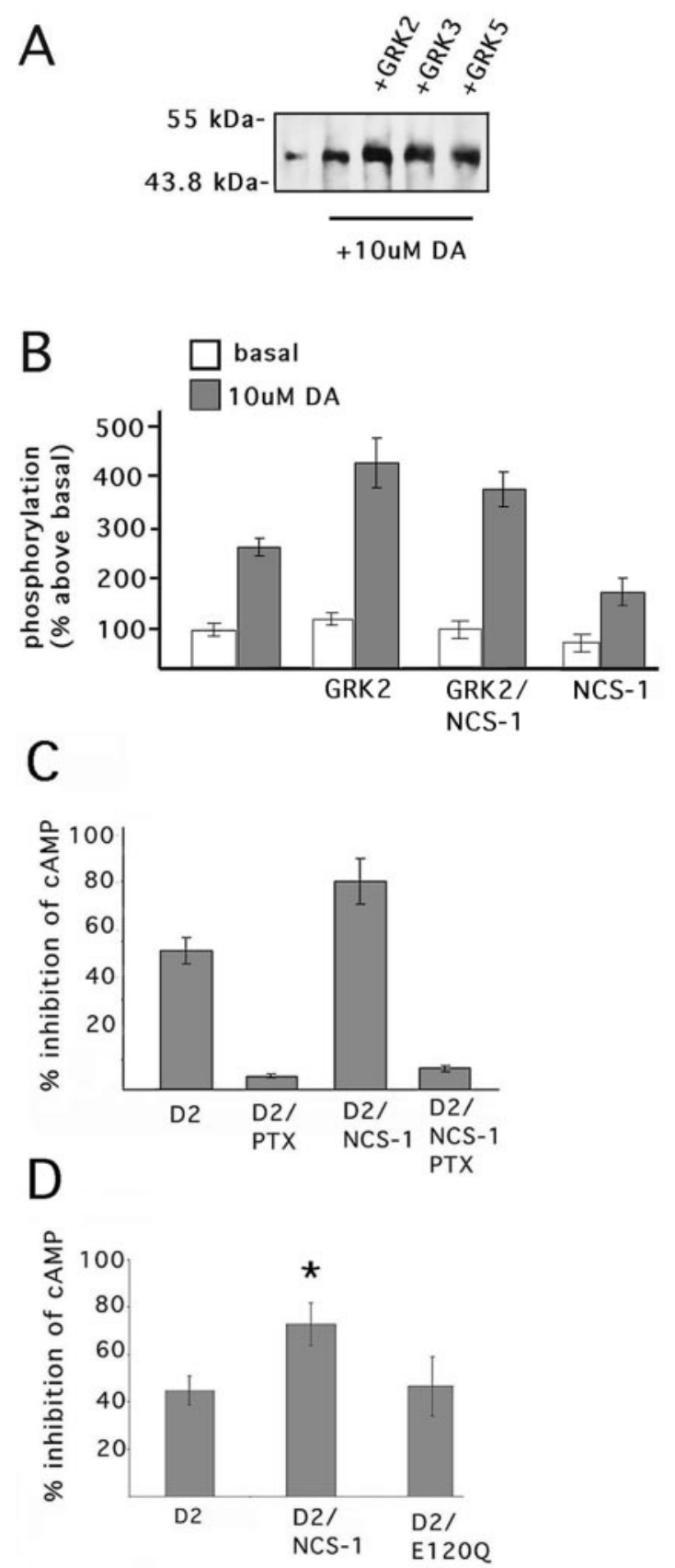

Figure 7. NCS-1 overexpression attenuates D2 receptor phosphorylation and increases D2 receptor signaling. D2 receptor phosphorylation was assayed by immunoprecipitation with an anti-FLAG M2 after a $10 \mathrm{~min}$ stimulation with $10 \mu \mathrm{M}$ dopamine. $A, 293-\mathrm{D} 2$ cells were transiently transfected with GRK2, GRK3, or GRK5 cDNA. B, 293-D2 cells were transiently transfected with GRK2, GRK2 plus EGFP-NCS-1, or EGFP-NCS-1 alone. $C, D, 293-\mathrm{D} 2$ cells were transiently transfected with EGFPNCS-1, EGFP-E120Q, or EGFP alone. Total cAMP levels were measured in cells treated for $5 \mathrm{~min}$ with $100 \mu \mathrm{M}$ forskolin followed by a $10 \mathrm{~min}$ exposure to $10 \mu \mathrm{M}$ dopamine. $C$, Transfected 293-D2 cells were incubated with $100 \mu \mathrm{g} / \mathrm{ml}$ pertussis toxin for $12 \mathrm{hr}$ before the assay. Error bars indicate SEM. Statistical analysis was performed using a one-way ANOVA; $n=9 ;{ }^{*} p<0.05$.

the NCS-1 immunoprecipitate, whereas no band was detected when lysates were immunoprecipitated with an irrelevant antibody. Interaction between these proteins is therefore likely to

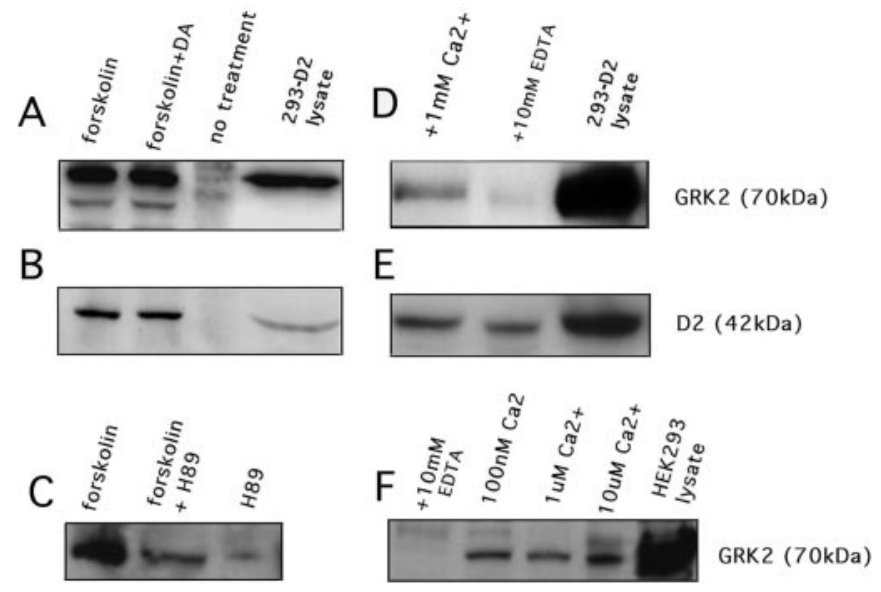

Figure 8. Interaction of NCS-1 with D2 receptors and GRK2. $A$, AntiNCS-1 antibody was used to immunoprecipitate endogenous NCS-1 from crude membrane fractions of 293-D2 cells. Immunocomplexes were probed using anti-GRK2 antibodies. $B$, The blot in $A$ was stripped and reprobed with anti-D2 receptor antibodies. $C$, Anti-NCS-1 antibody was used to immunoprecipitate endogenous NCS-1 from crude membrane fractions of 293-D2 cells that were treated with forskolin, pretreated with $\mathrm{H}-89$, or exposed to $\mathrm{H}-89$ alone. The blot was probed with anti-GRK2 antibodies. D, GST-NCS-1 fusion protein was used to pull-down endogenous GRK2 from lysates prepared from 293-D2 cells. Pull-downs were performed in the presence of either $1 \mathrm{mM} \mathrm{Ca}^{2+}$ or $10 \mathrm{~mm}$ EDTA. The blot was probed using an anti-GRK2 antibody. $E$, The blot in $D$ was stripped and reprobed using anti-D2 receptor antibodies. $F$, GST-NCS-1 fusion protein was used to pull-down endogenous GRK2 from HEK 293 cells lysate. Pull-downs were performed in the presence of $100 \mathrm{nM}, 1 \mu \mathrm{M}$, $10 \mu \mathrm{M}$ calcium, or in the presence of $10 \mathrm{~mm}$ EDTA. The blot was probed using anti-GRK2 antibodies.

play an important role in modulating signaling through the D2 dopamine receptor.

\section{DISCUSSION}

We have demonstrated that D2 dopamine receptors can functionally interact with NCS-1, a member of the neuronal calcium sensor family of EF hand calcium-binding proteins (Burgoyne and Weiss, 2001). NCS-1 is highly conserved throughout evolution, and orthologs have been identified in yeast, Drosophila, Caenorhabditis elegans, as well as rodents and humans (Pongs et al., 1993; Hendricks et al., 1999; Paterlini et al., 2000; Bourne et al., 2001). In invertebrate species, the NCS-1 ortholog frequenin has been implicated in mediating various aspects of neurotransmission, including $\mathrm{K}^{+}$channel activation (Poulain et al., 1994; Nakamura et al., 2001), $\mathrm{Ca}^{2+}$ channel inhibition and neurotransmitter release (Rivosecchi et al., 1994; Angaut-Petit et al., 1998; Wang et al., 2001). Furthermore, vertebrate NCS-1 has also been shown to regulate similar aspects of neurotransmission, as well as inhibit GRK1-mediated phosphorylation of rhodopsin (DeCastro et al., 1995; Nef et al., 1995). The results presented in this study implicate NCS-1 in regulation of neurotransmission through a direct interaction with dopamine receptors. Our data indicates that NCS-1 is anatomically positioned to regulate D2 receptor signaling at sites of synaptic activity. Regulation of D2 receptor desensitization by NCS-1 may therefore contribute to features of dopaminergic transmission.

NCS-1 belongs to the recoverin subfamily of EF hand calcium sensor proteins (Burgoyne and Weiss, 2001). Adaptations in light sensitivity by rhodopsin are critically dependent on the role of recoverin in mediating rhodopsin kinase phosphorylation and 

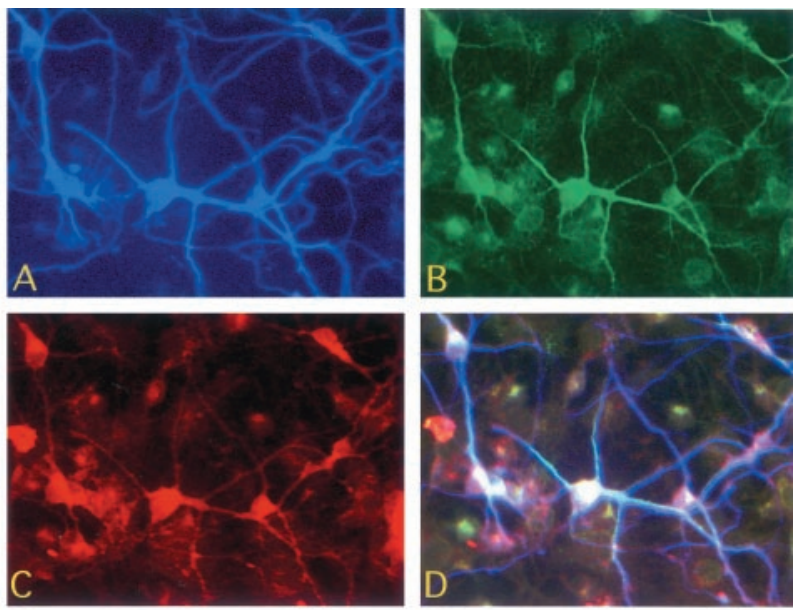

$\mathrm{E}$

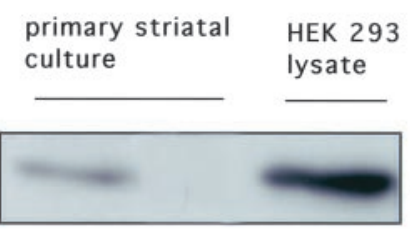

GRK2

IP: NCS-1 +

\section{IB: anti-GRK2}

Figure 9. Coexpression of D2 receptors, NCS-1, and GRK2 in primary striatal cultures. Epifluorescent detection of NCS-1 $(A)$, D2 receptor $(B)$, and GRK2 $(C)$ triple labeling within striatal neurons. The merged image $(D)$ shows coexpression of the three proteins within striatal neurons. $E$, Interaction of NCS-1 and GRK2 in striatal cultures. Anti-NCS-1 antibody was used to immunoprecipitate endogenous NCS-1 from lysates of primary striatal cultures. Immunocomplexes were probed with anti-GRK2 antibody. GRK2 was detected in lysates from striatal cell cultures as well as HEK 293 cells. GRK2 immunoreactivity was not detected when striatal lysates were immunoprecipitated with a nonspecific $(-)$ antibody.

desensitization of rhodopsin (Calvert et al., 1995). To address the hypothesis that NCS-1 may perform cellular functions similar to recoverin, we examined the effects of NCS-1 overexpression on D2 receptor desensitization. Our data indicate that NCS-1 expression causes a decrease in D2 receptor phosphorylation in response to ligand activation. By decreasing D2 receptor phosphorylation, NCS-1 appears to attenuate D2 receptor internalization. This process is likely to occur in a calcium-sensitive manner. This proposed mechanism is supported by the fact that the calcium-binding NCS-1 mutant (E120Q) cannot functionally substitute for wild-type NCS-1 in transfected cells. In addition, the finding that NCS-1 was found in association with D2 dopamine receptors and GRK2 in transfected cells and primary neurons strongly suggests that NCS-1 is likely to be involved in modulating GRK2-mediated desensitization of the D2 receptor. Our data also indicates that NCS-1-GRK2 interaction occurs in a calcium-dependent manner and that the E120Q NCS-1 mutant fails to block D2 receptor desensitization. Together, these results are consistent with the view that NCS-1-GRK2 interaction plays a key role in regulating signaling through the $\mathrm{D} 2$ receptor. Thus, recoverin and NCS-1 appear to play similar roles in attenuating desensitization of rhodopsin and dopamine receptors, respectively.

We found that the level of the NCS-1-GRK2-D2 receptor complex was significantly increased after treatment of cells with the adenylyl cyclase activator forskolin, raising the possibility that formation of the NCS-1-GRK2-D2 receptor complex may also be mediated via PKA activation. Our data indicate that treatment of HEK 293 cells (stably expressing the D2 receptor) with the PKA-inhibitor H-89 significantly attenuated the interaction between NCS-1 and GRK2. This result suggests that PKA activation is likely to participate in the formation of the NCS-1GRK2-D2 receptor complex. This is consistent with the observation that both PKA- and GRK-mediated phosphorylation events play a critical role in the desensitization of dopamine receptors (Jiang and Sibley, 1999). In addition, GRK2 itself is subject to PKA regulation, a process that is critical for the plasma membrane targeting and activation of GRK2 (Pitcher et al., 1998; Cong et al., 2001). The phosphorylation of GRK2 by PKA may therefore represent a mechanism by which GRK2 can associate with membrane proteins, including NCS-1. Alternatively, forskolin treatment may promote NCS-1-GRK2-D2 complex formation via a rise in intracellular calcium levels. Previous studies have shown that activation of cAMP-signaling pathways is associated with increased calcium release from intracellular stores (Wojcikiewicz and Luo, 1998; Zanassi et al., 2001). NCS-1-GRK2-D2 complex formation therefore may be promoted by an increase in $\left[\mathrm{Ca}^{2+}{ }_{\mathrm{i}}\right]$ after forskolin treatment. In this regard, it is interesting to note that within the brain NCS-1 and D2 receptors were often found to be associated with the spine apparatus, a site of intracellular calcium storage (Berridge, 1998). The positioning of NCS-1 and D2 receptors in close proximity to intracellular calcium stores supports the hypothesis that changes in intracellular calcium may regulate the effects of NCS-1 on D2 receptor signaling.

The fact that NCS-1 can regulate desensitization of D2 dopamine receptors supports the hypothesis that NCS proteins are likely direct regulators of GPCR signaling (Iacovelli et al., 1999). For example, recoverin has been shown to inhibit the phosphorylation of rhodopsin by GRK1 (Calvert et al., 1995; Chen et al., 1995), whereas visinin-like proteins VILIP-1 and VILIP-3 have been shown to attenuate GRK2-mediated phosphorylation of the M2 muscarinic receptor (Kato et al., 1998). Members of the NCS family may thus play a general role in receptor signaling by interacting with subtypes of GRKs to regulate receptor desensitization. It is possible that NCS proteins exert calcium sensitivity on the signaling properties of GPCRs. Indeed, the activity of many GPCRs, including substance P, angiotensin II, and dopamine receptors, is coupled to fluctuations in intracellular calcium (Muallem and Wilkie, 1999; Bofill-Cardona et al., 2000). The regulation of GRK-mediated desensitization by NCS proteins may therefore provide a feedback mechanism for regulating GPCR signaling. In this context, it is interesting to note that the ubiquitous calcium sensor calmodulin has also been shown to regulate the activity of GRKs (Chuang et al., 1996; Pronin et al., 1997). However, NCS-1 exhibits an $\sim 10$-fold higher affinity for calcium than does calmodulin (Cox et al., 1994), thus providing a mechanism whereby NCS-1 can modulate receptor-mediated signaling at lower intracellular calcium concentrations than calmodulin.

In directed yeast two hybrid screens, we also detected interaction between NCS-1 and D3 (D2-like) and D5 (D1-like) dopamine receptors. It will clearly be of interest to determine the physiological significance of NCS-1 interaction with each of the different dopamine receptor subtypes. Truncation mapping identified a 9-amino acid-long segment located in the $\mathrm{C}$ terminus of the D2 receptor that is responsible for binding NCS- 1 . The 
identical sequence is present in the $C$ terminus of the D3 receptor, suggesting that this segment also represents the site of D3NCS-1 interaction. BLAST analysis failed to identify a region of sequence homology, either in the $\mathrm{C}$ terminus or any other segment, within the D5 dopamine receptor. Because biochemical experiments support the validity of the D5 receptor-NCS-1 interaction (Kabbani, unpublished observations), it seems likely that alternative sequence motifs may be capable of contributing to the interaction between NCS-1 and different dopamine receptor subtypes. The interaction of NCS-1 with the D5 receptor raises another issue of interest. D1-like and D2-like dopamine receptors are believed to signal via distinct second messenger pathways (Missale et al., 1998). In the striatum, D1 and D2 receptors have been shown to colocalize within postsynaptic sites (Aizman et al., 2000). Our studies indicate that within striatum, NCS-1 expression is abundant in dendritic shafts and spines, raising the possibility that NCS-1 can mediate postsynaptic functions including cross-talk between D1-like and D2-like receptor-signaling pathways. The fact that NCS-1-GRK2-D2 receptor complex formation appears to be promoted by increases in intracellular cAMP and calcium levels suggests that signaling through the D2 receptor can be functionally coupled to the activation of $\left(G_{q}\right.$ and $\left.G_{s / o l f}\right)$ pathways known to be associated with D1-like receptors (Wang et al., 1995; Jin et al., 2001).

Previous studies have shown that NCS-1 functions to regulate calcium-dependent neurotransmitter release (McFerran et al., 1998; Chen et al., 2001; Guild et al., 2001) and $\mathrm{Ca}^{2+}$ channel activity (Weiss et al., 2000; Tsujimoto et al., 2002). Therefore, it is tempting to speculate that NCS-1-D2 receptor interaction may also provide a functional link between D2 receptors and other synaptic proteins. Because NCS-1 appears to play a pivotal role in regulating dopamine receptor function, it will be important to determine if there are alterations in NCS-1 structure and function in neuropathologies associated with dysregulation in dopaminergic signaling.

\section{REFERENCES}

Aizman O, Brismar H, Uhlen P, Zettergren E, Levey AI, Forssberg H, Greengard P, Aperia A (2000) Anatomical and physiological evidence for D1 and D2 dopamine receptor colocalization in neostriatal neurons. Nat Neurosci 3:226-230.

Angaut-Petit D, Toth P, Rogero O, Faille L, Tejedor FJ, Ferrus A (1998) Enhanced neurotransmitter release is associated with reduction of neuronal branching in a Drosophila mutant overexpressing frequenin. Eur J Neurosci 10:423-434.

Berridge MJ (1998) Neuronal calcium signaling. Neuron 21:13-26.

Bofill-Cardona E, Kudlacek O, Yang Q, Ahorn H, Freissmuth M, Nanoff C (2000) Binding of calmodulin to the D2-dopamine receptor reduces receptor signaling by arresting the G-protein activation switch. J Biol Chem 275:32672-32680.

Bourne Y, Dannenberg J, Pollman V, Marchot P, Pongs O (2001) Immunocytochemical localization and crystal structure of human frequenin (neuronal calcium sensor 1). J Biol Chem 276:11949-11955.

Brewer CB, Roth MG (1991) A single amino acid change in the cytoplasmic domain alters the polarized delivery of influenza virus hemagglutinin. J Cell Biol 114:413-421.

Burgoyne RD, Weiss JL (2001) The neuronal calcium sensor family of $\mathrm{Ca}^{2+}$ binding proteins. Biochem J 353:1-12.

Calvert PD, Klenchin VA, Bownds MD (1995) Rhodopsin kinase inhibition by recoverin. J Biol Chem 270:24127-24129.

Chen CK, Ingelese J, Lefkowitz RJ, Hurley JB (1995) Ca2+-dependent interaction of recoverin with rhodopsin kinase. J Biol Chem 270:18060-18066.

Chen XL, Zhong ZG, Yokoyama S, Bark C, Meister B, Berggren PO, Roder J, Higashida H, Jeromin A (2001) Overexpression of rat neuronal calcium sensor-1 in rodent NG108-15 cells enhances synapse formation and transmission. J Physiol (Lond) 532:649-659.

Chuang TT, Paolucci L, De Blasi A (1996) Inhibition of G proteincoupled receptor kinase subtypes by $\mathrm{Ca}^{2+}$-calmodulin. J Biol Chem 271:28691-28696.
Civelli O, Bunzow JR, Grandy DK (1993) Molecular diversity of the dopamine receptors. Annu Rev Pharmacol Toxicol 32:281-307.

Cong M, Perry SJ, Lin FT, Fraser ID, Hu LA, Chen W, Pitcher JA, Scott JD, Lefkowitz RJ (2001) Regulation of membrane targeting of the G protein coupled receptor kinase 2 by protein kinase $\mathrm{A}$ and its anchoring protein AKAP79. J Biol Chem 276:15192-15199.

Cox JA, Drussel I, Comte M, Nef S, Nef P, Lenz SE, Gundelfinger ED (1994) Cation binding and conformational changes in VILIP and NCS-1, two neuron-specific calcium-binding proteins. J Biol Chem 269:32807-32813.

DeCastro E, Nef S, Fiumelli H, Lenz SE, Kawamura S, Nef P (1995) Regulation of rhodopsin phosphorylation by a family of neuronal calcium sensors. Biochem Biophys Res Commun 216:133-140.

Ferguson SSG (2001) Evolving concepts in G-protein coupled receptor endocytosis: the role of receptor desensitization and signaling. Pharmacol Rev 53:1-24.

Guild SB, Murray AT, Wilson ML, Wiegand UK, Apps DK, Jin Y, Rindler M, Roder J, Jeromin A (2001) Over-expression of NCS-1 in AtT-20 cells affects ACTH secretion and storage. Mol Cell Endocrinol 184:51-63.

Hendricks KB, Wang BQ, Schnieders EA, Thorner J (1999) Yeast homologue of neuronal frequenin is a regulator of phosphatidylinositol4-OH kinase. Nat Cell Biol 1:234-241.

Henn FA (1986) Neurotransmitter abnormalities in schizophrenia. In: Biological perspectives of schizophrenia (Helmcehn H, Henn FA, eds), pp 299-310. New York: Wiley.

Iacovelli L, Sallese M, Mariggio S, De Blasi A (1999) Regulation of G-protein-coupled receptor kinase subtypes by calcium sensor proteins. FASEB 13:1-8.

Ito K, Haga T, Lameh J, Sadee W (1999) Sequestration of dopamine D2 receptors depends on coexpression of G-protein-coupled receptor kinases 2 or 5. Eur J Biochem 260:112-119.

Iwata K, Ito K, Fukuzaki A, Inaki K, Haga T (1999) Dynamin and Rab5 regulate GRK2-dependent internalization of dopamine D2 receptors. Eur J Biochem 263:596-602.

Jiang D, Sibley DR (1999) Regulation of D1 dopamine receptors with mutations of protein kinase phosphorylation sites: attenuation of the rate of agonist-induced desensitization. Mol Pharmacol 56:675-683.

Jin LQ, Wang HY, Friedman E (2001) Stimulated D(1) dopamine receptors couple to multiple $\mathrm{G}$ alpha proteins in different brain regions. J Neurochem 78:981-990.

Karpa K, Lin R, Kabbani N, Levenson R (2000) The dopamine D3 receptor interacts with itself and the truncated D3 splice variant D3nf: D3-D3nf interaction causes mislocalization of D3 receptors. Mol Pharmacol 58:677-683.

Kato M, Watanabe Y, Lino S, Takaoka Y, Kobayashi S, Haga T, Hidaka $\mathrm{H}$ (1998) Cloning and expression of a cDNA encoding a new neurocalcin isoforms (neurocalcin a) from bovine brain. Biochem J 331:871-876.

Kim KM, Valenzano KJ, Robinson SR, Yao WD, Barak LS, Caron MG (2001) Differential regulation of the dopamine D2 and D3 receptors by $\mathrm{G}$ protein-coupled receptor kinases and $\beta$-arrestins. J Biol Chem 276:37409-37414.

Krupnick JG, Benovic JL (1998) The role of receptor kinases and arrestins in G-protein-coupled receptor regulation. Annu Rev Pharmacol Toxicol 32:289-319.

Levey AI, Hersch SM, Rye DB, Sunahara RK, Niznik HB, Kitt CA, Price DL, Maggio R, Brann MR, Ciliax BJ (1993) Localization of D1 and D2 dopamine receptors in brain with subtype-specific antibodies. Proc Natl Acad Sci USA 90:8861-8865.

Lin R, Karpa K, Kabbani N, Goldman-Rakic P, Levenson R (2001) Dopamine D2 and D3 receptors are linked to the actin cytoskeleton via interaction with Filamin A. Proc Natl Acad Sci USA 98:5258-5263.

Lohse MJ (1993) Molecular mechanisms of membrane receptor desensitization. Biochim Biophys Acta 1179:171-188.

Mason JN, Kozell LB, Neve KA (2002) Regulation of dopamine D1 receptor trafficking by protein kinase A-dependent phosphorylation. Mol Pharmacol 61:806-816.

McFerran BW, Graham ME, Burgoyne RD (1998) Neuronal calcium sensor 1 , the mammalian homologue of frequenin, is expressed in chromaffin and PC12 cells and regulates neurosecretion from dense core granules. J Biol Chem 273:22768-22772.

McFerran BW, Weiss JL, Burgoyne RD (1999) Neuornal calcium sensor1. Characterization of the myristoylated protein, its cellular effects in permeabilized adrenal chromaffin cells, $\mathrm{Ca}^{2+}$-independent membrane association, and interaction with binding proteins, suggesting a role in rapid $\mathrm{Ca}^{2+}$ signal transduction. J Biol Chem 274:30258-30265.

Missale C, Nash R, Robinson SW, Jaber M, Caron MG (1998) Dopamine receptors: from structure to function. Pharmacol Rev 78:189-225.

Mrzljak L, Levey AI, Belcher S, Goldman-Rakic PS (1998) Localization of the $\mathrm{m} 2$ muscarinic acetyl-choline receptor protein and mRNA in cortical neurons of the normal and cholinergically deafferented rhesus monkey. J Comp Neurol 390:112-132.

Muallem S, Wilkie TM (1999) G protein-dependent $\mathrm{Ca}^{2+}$ signaling complexes in polarized cells. Cell Calcium 26:173-180. 
Nakamura TY, Pountney DJ, Ozaita A, Nandi S, Ueda S, Rudy B, Coetzee WA (2001) A role for frequenin, a $\mathrm{Ca}^{2+}$-binding protein, as a regulator of $\mathrm{Kv} 4 \mathrm{~K}^{+}$-currents. Proc Natl Acad Sci USA 98:12808-12813.

Nef S, Fiumelli H, DeCastro E, Raes MB, Nef P (1995) Identification of a neuronal calcium sensor (NCS-1) possibly involved in the regulation of receptor phosphorylation. J Recept Signal Transduct Res 15:365-378.

Nestler EJ (1995) Molecular basis of addictive states. The Neuroscientist $1: 212-220$.

Olfasson P, Wang T, Lu B (1995) Molecular cloning and functional characterization of the Xenopus $\mathrm{Ca}^{2+}$-binding protein frequenin. Proc Natl Acad Sci USA 92:8001-8005.

Pan CY, Jeromin A, Lundstrom K, Yoo SH, Roder J, Fox AP (2002) Alterations in exocytosis induced by neuronal calcium sensor-1 in bovine chromaffin cells. J Neurosci 22:2427-2433.

Paterlini M, Revilla V, Grant AL, Wisden W (2000) Expression of the neuronal calcium sensor protein family in the rat brain. Neuroscience 99:205-216.

Pawson T, Scott JD (1997) Signaling through scaffold, anchoring, and adaptor proteins. Science 278:2075-2080.

Pitcher JA, Freedman NJ, Lefkowitz R (1998) G protein-coupled receptor kinases. Annu Rev Biochem 67:653-692.

Pongs O, Lindemeier J, Zhu XR, Theil T, Engelkamp D, Krah-Jentgens I, Lambrecht HG, Koch KW, Schwemer J, Rivosecchi R, Mallart A, Galceran J, Canal I, Barbas JA, Ferrus A (1993) Frequenin-a novel calcium binding protein that modulates synaptic efficacy in the Drosophila nervous system. Neuron 11:15-28.

Poulain C, Ferrus A, Mallart A (1994) Modulation of type A K+ current in Drosophila larval muscle by internal $\mathrm{Ca}^{2+}$; effects of the overexpression of frequenin. Pflügers Arch 427:71-79.

Pronin AN, Satpaev DK, Slepak VZ, Benovic JL (1997) Regulation of G protein coupled receptor kinases by calmodulin and localization of the calmodulin binding domain. J Biol Chem 272:18273-18280.

Rivosecchi R, Pongs O, Theil T, Mallart A (1994) Implication of frequenin in the facilitation of transmitter release in Drosophila. J Physiol (Lond) 474:223-232.

Sallese M, Iacovelli L, Cumashi A, Capobianco L, Cuomo L, De Blasi A (2000) Regulation of G protein-coupled receptor kinase subtypes by calcium sensor proteins. Biochem Biophys Acta 1498:112-121.
Scalettar BA, Rosa P, Taverna E, Francolini M, Tsuboi T, Terakawa S, Koizumi S, Roder J, Jeromin A (2002) Neuronal calcium sensor-1 binds to regulated secretory organelles and functions in basal and stimulated exocytosis in PC12 cells. J Cell Sci 115:2399-2412.

Sealfon SC, Olanow CW (2000) Dopamine receptors: from structure to behavior. Trends Neurosci 23:S34-S40.

Seeman P (1992) Dopamine receptor sequences. Therapeutic levels of neuroleptics occupy D2 receptors, clozapine occupies D4. Neuropsychopharmacology 7:261-284.

Self DW (1998) Neural substrates of drug craving and relapse in drug addiction. Ann Med 30:379-389.

Tiberi M, Nash SR, Bertrand L, Lefkowitz RJ, Caron MG (1996) Differential regulation of dopamine D1A receptor responsiveness by various G protein-coupled receptor kinases. J Biol Chem 271:3771-3778.

Tsujimoto T, Jeromin A, Saitoh N, Roder JC, Takahashi T (2002) Neuronal calcium sensor-1 and activity dependent facilitation of P/Q-type calcium currents at presynaptic nerve terminals. Science 295:2276-2279.

Vickery RG, von Zastrow M (1999) Distinct dynamin-dependent and -independent mechanisms target structurally homologous dopamine receptors to different endocytotic membranes. J Cell Biol 144:31-43.

Wang CY, Yang F, He X, Chow A, Du J, Russell JT, Lu B (2001) $\mathrm{Ca}^{2+}$ binding protein frequenin mediates GDNF-induced potentiation of $\mathrm{Ca}^{2+}$ channels and transmitter release. Neuron 32:99-112.

Wang HY, Undie AS, Friedman E (1995) Evidence for the coupling of Gq protein to D1-like dopamine sites in rat striatum: possible role in dopamine-mediated inositol phosphate formation. Mol Pharmacol 48:988-994.

Weiss JL, Archer DA, Burgoyne RD (2000) NCS-1/frequenin functions in an autocrine pathway regulating $\mathrm{Ca}^{2+}$ channels in bovine adrenal chromaffin cells. J Biol Chem 275:40082-40087.

Wojcikiewicz RJH, Luo SG (1998) Phosphorylation of inositol 1, 4, 5-triphosphate receptors by cAMP-dependent protein kinase. J Biol Chem 273:5670-5677.

Zanassi P, Paolillo M, Feliciello A, Avvedimento EV, Gallo V, Schinnelli S (2001) cAMP-dependent protein kinase induces cAMP-response element binding protein phosphorylation via intracellular calcium release/ERK-dependent pathway in striatal neurons. J Biol Chem 276: $11487-11495$ 